\title{
1 The effects of maternal social connectivity and integration on offspring survival in a
}

2 marmot

3

4 Running Head: Effects of maternal social relationships

5

6 Anita Pilar Montero ${ }^{1}$, Dana M. Williams ${ }^{1,2}$, Julien G.A. Martin ${ }^{1,3}$, and Daniel T.

7 Blumstein ${ }^{1,2}$

8

$9 \quad{ }^{1}$ Rocky Mountain Biological Laboratory, Box 519, Crested Butte, CO 81224, USA

$10{ }^{2}$ Department of Ecology and Evolutionary Biology, 621 Young Drive South, University

11 of California, Los Angeles, CA 90095-1606, USA

$12{ }^{3}$ Department of Biology, University of Ottawa, 30 Marie Curie, Ottawa, ON, K1N 6N5,

13 Canada

*Correspondence: Daniel T. Blumstein (310) 267-4746, marmots@ucla.edu) twitter: (a)TeamMarmot

\section{Lay Summary}

17 Maternal social relationships can impact offspring survival but much of what we know

18 about these effects comes from studies of obligately social species. In faculatively social

19 yellow-bellied marmots we found that pups born to mothers who received more

20 affiliative interactions were less likely to survive while the offspring of mothers who

21 were more highly integrated into agonistic networks had enhanced survival. Overall, pups

22 are influenced by their mother's social world, often in contradictory ways. 


\section{Abstract}

In social species, maternal social relationships, in addition to direct care, impact offspring survival but much of what we know about these effects comes from studies of obligately social and cooperatively breeding species. Yellow-bellied marmots (Marmota flaviventer) are a facultatively social species whose social groups vary in composition, size, and cohesiveness. This natural variation in sociality and cooperative breeding behavior makes yellow-bellied marmots an ideal species within which to study the effects of maternal affiliative and agonistic social behavior on offspring. We used social network analysis to investigate the relationship between maternal social connectivity and integration on offspring summer and yearly survival, with the hypothesis that offspring with more affiliative mothers are more likely to survive than the offspring of more agonistic mothers. However, we found the inverse to be true: pups born to mothers who received more affiliative interactions were less likely to survive while the offspring of mothers who were more highly integrated into agonistic networks had enhanced survival.

Overall, maternal social network measures were positively and negatively correlated with often in contradictory ways. Relative predation risk and colony location also mediated the 
Key Words: maternal effects, sociality, predation, alloparental care, yellow-bellied marmot

Introduction

Many taxa exhibit maternal care, where the degree and quality of care directly 
2002, da Silva Mota et al. 2006). This system dramatically increases juvenile survival (Blumstein and Armitage 1999). In cichlids (Neolamprologus pulcher), a cooperative breeding fish, breeding individuals are more connected within their social network than helpers (Dey et al. 2013), indicating that a breeding female's relationships may work to enforce breeding exclusivity by allowing the dominant individual to police the behaviors of helpers, ensuring better offspring care and outcomes. Clearly there exists a complex relationship between maternal social relationships, maternal care, and offspring outcomes in a variety of species.

Yellow-bellied marmots (Marmota flaviventer) (henceforth, 'marmots'), a large, ground-dwelling alpine rodent (Armitage 2014) classified as semi-cooperative breeders (Blumstein and Armitage 1999), are an ideal species within which to study this phenomena. Marmots are considered facultatively social animals (Blumstein and Armitage 1999) due to the phenotypic plasticity of their sociality; they are capable of both solitary and group living (Huang et al. 2011). Marmot groups vary in size, age, sex demographics and social dynamics (le Roux et al. 2008), and vary in their degree of social interaction according to environmental conditions (Barash 1973). Facultatively social individuals do not need to be social to survive, and therefore have chosen to interact with others either due to some beneficial aspect of their relationships, or because they were forced into group living due to environmental constraints.

Previous work found that more social yearling and adult females who live in large groups were more likely to survive the summer, showing that an individual's security is affected by their relationships (Montero et al. 2019). Marmots also partially fulfill 
Solomon and French's (1997) three cooperative breeding criteria: 1) Pups postpone dispersal past reproductive maturity to the yearling stage; 2) Individuals provide alloparental care in the form of alarm calling, group hibernation, and communal nursing; and 3) There is some degree of reproductive suppression of subordinate females, although more than a single matrilineal female breeds (Blumstein and Armitage 1999). However, none of this breeding behavior is obligate and marmots can live and successfully reproduce in groups that fit none of these criteria (Blumstein and Armitage 1999). This gives us the opportunity to study marmot social groups which exhibit varying degrees of cooperative breeding and draw conclusions about the benefits that maternal social relationships confer on offspring.

Despite the social nature of their reproductive system, marmots seem to experience severe costs of sociality. More social marmots have decreased longevity (Blumstein et al. 2018) and, in particular, increased over-winter mortality (Yang et al. 2017). Additionally, more social females have reduced reproductive success (Wey and Blumstein 2010), a characteristic of reproductive suppression. Adult females (many of whom are mothers) continue to engage in potentially costly affiliative relationships even when they themselves only benefit from group size (Montero et al. 2019). This suggests that other group members (perhaps their offspring) may receive the benefits of sociality. Additionally, while the interaction of sociality and survival has been analyzed in yearlings and adults, it has not been addressed for pups.

Thus, to determine whether maternal relationships benefit pups, we focus here on how maternal social network position is associated with offspring survival. We expect 
111 that pups born to more affiliatively socially integrated mothers have a higher likelihood

112 of both summer and yearly survival. Conversely, we expect that pups born to mothers

113 who are more integrated in agonistic networks are less likely to survive. This study

114 investigates a new potential benefit (and cost) of sociality and the effect of social security

115 (Blumstein et al. 2017, Mady and Blumstein 2017, Fuong and Blumstein 2019) in

116 marmot social groups, with potential implications for other cooperative breeding and

117 facultatively social species.

\section{Methods}

\section{The study system}

121

122

We studied marmots in and around the Rocky Mountain Biological Laboratory (RMBL) (3857’29”N, 10659’06”W, elevation 2890 m), in the Upper East River Valley in Gunnison County, Colorado, USA. The research was performed with approvals from the UCLA Animal Care Committee (research protocol ARC 2001-191-01) and permits issued from the Colorado Division of Wildlife (TR-519). The marmot population at RMBL has been studied since 1962 (Armitage 2014), and therefore we have long-term data on individuals' births and deaths (allowing us to calculate accurate ages) and group and colony lineages. A colony is a geographic location that contains one or more marmot social groups. Social groups consist of resident adult females who are maternally related, yearlings (one year old juveniles), pups (juveniles $<4$ months old), and one or more adult males (Armitage 1991). Three to 4 week old pups emerge from the natal burrow in July (Armitage 1987). Litters average approximately 4 pups at emergence but can range from 
1331 to 9 pups. Pup survival differs between colonies, but on average roughly $50 \%$ of

134 juveniles survive to age 1 year (Schwartz et al. 1998).

136 four colony sites: Bench-River, the Gothic Townsite, Picnic, and Marmot Meadow.

137 Bench-River and the Gothic Townsite are lower elevation sites and we refer to them as

138 “down-valley." Picnic and Marmot Meadow are higher elevation sites and are therefore

139 considered "up-valley." Prior work has shown that marmot life history traits, such as

140 body mass, vary as a function of valley position (Van Vuren and Armitage 1991). We

141 selected these sites because we have detailed information on the social interactions that

142 occur at these colonies, these social interactions are highly variable, and the colonies

143 themselves are geographically distinct.

\section{Trapping}

To identify individuals and obtain morphological data and samples, marmots at all

four colonies were trapped using Tomahawk live traps baited with horse feed. Every

individual at each colony was trapped at least once during the active season (mid-April to mid-September) each year (trapping procedures described in more detail in Armitage 1982). The first time an individual was trapped they were given metal ear tags for permanent identification and temporary dorsal pelage dye marks (using nontoxic Nyanzol-D dye), for observational identification. Hair samples were also collected from trapped individuals for later parentage assignment (Blumstein et al. 2010), and reproductive status noted (more detailed trapping procedures outlined in Armitage 1982). 


\section{Behavioral observations}

To collect data on marmot social interactions, near daily observations were

performed during periods of peak activity (0700-1000 $\mathrm{h}$ and 1600-1900 h), weather

permitting, during the active season. Researchers sat at distances that did not influence marmot behavior and observed marmots using binoculars and 15-45 x spotting scopes. into agonistic interactions (fighting and displacements) or affiliative interactions (all ravens (Corvus corax)) at a colony during each observation period.

\section{Determining maternity}

To assign maternity to pups we used behavioral and genetic methods. Pups were trapped when they first emerged from the natal burrow and following emergence, predominately engaged in affiliative behaviors with their mothers. This, in conjunction with the identification of lactating mothers during trapping reproductive status assessment, allowed us to behaviorally match pups to mothers. DNA extracted from hair samples collected during trapping confirmed maternity (details in Blumstein et al. 2010). 


\section{Quantifying social relationships}

To quantify the social relationships of marmot mothers, we constructed affiliative and agonistic interaction matrices for each of the four colonies for each of the sixteen years of study (agonistic interactions: $n=3,902$, affiliative interactions: $n=31,630$ ). Using these matrices, we calculated two sets of ten social network measures (one set based on agonistic interactions and the other set based on affiliative interactions) for all mothers for each year.

The measures we calculated were indegree, outdegree, incloseness, outcloseness, betweenness centrality, eigenvector centrality, instrength, outstrength, negative average shortest path length, and local clustering. Indegree, based on received interactions, and outdegree, based on initiated interactions, are calculated based on the number of individuals with whom a focal individual interacts. These measures gage how directly an individual is connected to others in their network (Wasserman and Faust 1994). If maternal connectivity is positively associated with pup survival, the offspring of mothers with higher indegree and outdegree measures will have higher rates of survival.

Closeness centrality, measured as incloseness (received interactions) and outcloseness (initiated interactions), describes how influential a focal individual is within the network, and is calculated as the sum of the reciprocal of the shortest path length between the focal individual and all other individuals in the network (Wasserman and Faust 1994). We predict that more influential mothers will have offspring with greater chances of survival. An individual's centrality can also be measured as betweenness, which is the proportion 
of shortest path lengths between all pairs of individuals within the network that include the focal individual (Wey et al. 2008). Similar to closeness centrality, if maternal sociality is positively correlated with offspring survival, the offspring of more central mothers will have a greater chance of survival. Eigenvector centrality is another measure of connectedness, and it takes into account the indirect effects of relationships that occur between a focal individual's neighbors in addition to the focal individual's own position (Newman 2018). If a mother has a high degree of eigenvector centrality, her connections are highly connected, which we predict will increase her pups' chances of survival. Strength, measured as instrength (received interactions) and outstrength (initiated interactions), describes how frequently a focal individual interacts with their neighbors (Wasserman and Faust 1994). We hypothesize that stronger maternal relationships will result in greater pup survival. Average shortest path length is calculated as the average number of individuals in a path between the focal individual and another individual. It describes how efficiently a member of a network can connect with others (Newman 2018). If maternal connection is beneficial for pup survival, a more connected individual should experience greater offspring survival. For the purposes of this analysis we will be using negative average shortest path length, which allows a positive relationship between social integration and pup survival to result in a positive estimate. To understand the cliquishness of a network, clustering calculations generally divide the number of actual relationships formed by a focal individual by the total number of possible relationships (Wey et al. 2008). Local clustering describes an individual's embeddedness within their network (Wasserman and Faust 1994). We predict that local clustering will have a 
221 positive effect on pup survival, because more embedded marmots may receive more help

222 from their conspecifics.

\section{Data processing and analyses}

To account for key aspects of a marmot's environment that are not captured by social network measures, we calculated predator index and social network size. Predator index was based on the proportion of observation periods during which a predator was sighted in a given colony. We used a median split to define a binary measure of comparatively high and low predation pressure for each colony annually. Network size was calculated as the number of individuals in each social network. 
To determine the effect of a mother's social network measures on pup survival,

243 we fitted a series of generalized linear mixed effects models (GLMM) with binomial

error structures. Due to the different effects of social network measures on individuals,

we fitted a separate model for each social network measure in the agonistic and affiliative

included as fixed effects the focal social network measure, maternal age, valley position,

predation index, network size, pup emergence date, litter size, log of August mass (for

yearly survival models) or log of daily mass gain (for summer survival), an interaction

term between the focal social network measure and valley position, and an interaction and maternal identity as random effects.

(Bartoń 2019), lme4 (Bates et al. 2017), lmerTest (Kuznetsova et al. 2016), and optimx

(Nash and Varadhan 2011). We used the bobyqa optimizer for some models to obtain proper model convergence.

In the summer survival model based on affiliative interactions, 8 of the 10 models

revealed negative associations with affiliative social relationships. Of these, only

262 instrength was significant at the 0.05 level (Estimate $=-0.027, \mathrm{SE}=0.013, \mathrm{z}=-2.037, P$

$263=0.042$; Table 1; Figure 1a). Additionally, some models had significant interactions 
264 between the affiliative social network measure and predation index or valley position. In

265 the instrength model (Estimate $=0.030, \mathrm{SE}=0.015, \mathrm{z}=1.986, P=0.047)$, the indegree

266 model $($ Estimate $=3.183, \mathrm{SE}=1.599, \mathrm{z}=1.991, P=0.046)$, the outcloseness model

267 (Estimate $=6.837, \mathrm{SE}=2.408, \mathrm{z}=2.839, P=0.005)$, and the local clustering model

268 (Estimate $=2.480, \mathrm{SE}=1.162, \mathrm{z}=2.134, P=0.033$, the social measure-predation index

269 interaction showed a significant negative effect (Figure 1b, c, d, e), such that the above

270 maternal social measures were positively correlated with offspring success in low

271 predation environments. The interactions between valley position and outcloseness

272 (Estimate $=-5.099, \mathrm{SE}=2.191, \mathrm{z}=-2.328, P=0.020)$ and valley position and negative

273 average shortest path length (Estimate $=-0.887, \mathrm{SE}=0.446, \mathrm{z}=-1.990, P=0.047)$ had a

274 negative association with pup survival, indicating that maternal out closeness and

275 negative shortest path length are negatively correlated with offspring survival in Picnic

276 and Marmot Meadow (up valley) (Figure 1f, g). Up valley position was a significant

277 positive predictor of offspring survival in 9 models. Daily mass gain was positively

278 significant in all 10 models. Predation index was significant in 7 models, where survival

279 probability decreased with higher predation index. Other fixed effects included in the

280 affiliative summer survival models were not significant (see Supplementary Table S1 for

281 full model results).

\section{Impact of Maternal Affiliative Interactions on Offspring Yearly Survival}

Six of the 10 yearly survival models based on affiliative interactions had a 
the 10 models were positively associated. None of the positively associated models were

287 significant and, of the models showing a negative association, only instrength was

288

significant (Estimate $=-0.031, \mathrm{SE}=0.014, \mathrm{z}=-2.263, P=0.024$; Table 1; Figure 2a).

Up valley position was a significant positive predictor of offspring survival in 9 models.

August mass was positively significant in all 10 models. Predation index was significant

in 8 models, where survival probability decreased with higher predation index. Both

emergence date and network size were positively significant in 1 model. Other fixed

effects included in the affiliative yearly survival models were not significant (see

Supplementary Table S2 for full model results).

\section{Impact of Maternal Agonistic Interactions on Offspring Summer Survival}

Four of the 10 summer survival models based on agonistic interactions revealed negative associations with agonistic behavior while the other 6 models had positive associations. Of these models, 1 was significant: negative average shortest path length (Estimate $=1.362, \mathrm{SE}=0.534, \mathrm{z}=2.549, P=0.011$; Table 1; Figure 3a).

In three models, negative average shortest path length (Estimate $=-1.917, \mathrm{SE}=0.558, \mathrm{z}=$ $-3.434, P=0.001)$, outdegree $($ Estimate $=-5.596, \mathrm{SE}=1.897, \mathrm{z}=-2.950, P=0.003)$, and outcloseness (Estimate $=-3.149, \mathrm{SE}=1.552, \mathrm{z}=-2.029, P=0.043$ ), there was also a significant negative effect of the interaction of valley position and social network measures. Higher measure of these 3 social measures therefore have a significant negative effect on offspring survival in up valley environments (Figure 3b, c, d). Up valley position was a significant positive predictor of offspring survival in 9 models and a 
significant negative predictor off offspring survival in 1 model. Daily mass gain was

positively significant in 9 models. Predation index was significant in 8 models, where

311 in the agonistic summer survival models were not significant (see Supplementary Table

312 S3 for full model results).

\section{Impact of Maternal Agonistic Interactions on Offspring Yearly Survival}

Of the 10 yearly survival models, six models (indegree, betweenness, incloseness, negative average shortest path length, outstrength, and instrength) are singular fitted. model results reported for these six social network measures do not include august mass as a fixed effect. Six of the 10 yearly survival models based on agonistic interactions had a positive association between agonistic behavior and pup survival, of which only negative average shortest path length was significant $($ Estimate $=1.633, \mathrm{SE}=0.537, \mathrm{z}=$ 3.042, $P=0.002$; Table 1; Figure 4a). There was a significant negative interaction between negative average shortest path length and valley position (Estimate $=-1.468, \mathrm{SE}$ $=0.498, \mathrm{z}=-2.946, P=0.003)$, indicating that high measures of maternal negative

326 environments (Figure 4b). Up valley position was a significant positive predictor of offspring survival in 9 models. August mass was positively significant in 4 models. 
negatively significant in 1 model. Other fixed effects included in the agonistic yearly survival models were not significant (see Supplementary Table S4 for model results).

\section{Discussion}

We investigated the relationship between maternal social network connectivity and integration on offspring survival. We hypothesized that more socially integrated affiliative mothers would have higher rates of offspring survival, indicating a potential benefit of sociality for these facultatively social mammals. We expected to see the opposite effect among more agonistic mothers. We found complex results that suggest that both specific social attributes and environmental factors affect offspring survival in different ways. Social connectedness is neither universally good nor universally poor for marmots but pups are clearly affected by the social world of their mothers.

The strength of received affiliative relationships is associated with decreased pup survival over the first year. Conversely, pups are also more likely to survive if their mothers are more central in agonistic networks. Additionally, agonistic negative average shortest path length, rather than the occurrence or frequency of interactions, significantly explains variation in pup survival. This indicates that the pups of mothers who are highly connected to others through agonistic behavior are most successful. At first glance, these findings are contrary to our hypothesis; individuals are not able to seek out better outcomes for their offspring by maintaining strong affiliative relationships that could encourage alloparental care. However, mothers may encourage conspecific help through agonistic behavior, where agonism acts as a punishment intended to enforce altruistic 
352 alloparental behavior (in naked mole rats, Heterocephalus glaber, Reeve 1992, Clutton-

353 Brock and Parker 1995).

Dominance, while not included in this analysis, plays an important role in shaping

how an individual engages with conspecifics and affects offspring survival in many species (Ellis 1995). Dominant individuals may have access to high quality foraging territory (hyenas, Crocuta crocuta, Frank et al. 1995 and chimpanzees, Pan troglodytes, Pusey 1997), or they may have subordinates help through babysitting and supplemental feeding of offspring (meerkats, Suricata suricatta, Russell et al. 2002). In their study of cichlid social networks, Dey et al. (2013) found that dominant reproductive females (of which there is only one) had higher measures of centrality and overall relationship strength. Although marmot dominance is subtle, more dominant females exhibit more agonistic behavior and have greater reproductive success (Blumstein et al. 2016). Consistent with Dey et al.'s findings, we found that agonistic negative average shortest path length, a measure of maternal centrality, was significantly associated with increased offspring survival. Outstrength, a measure of relationship strength, was also consistently positively associated with offspring survival in three of the four model types, although not significantly so. Therefore, high measures of negative average path length and outstrength may correlate with more dominant individuals, thus enhancing pup survival. While marmots are generalist herbivores and unlikely to dominate food patches, other resources such as hibernacula are limited and may be dominated by females of higher rank, which would improve overwinter survival (Armitage 2014). Additionally, more dominant females may be better able to recruit yearling females as helpers, perhaps 
374 through bullying behavior, as discussed above. Yearling females are more likely to

375 disperse when they are less socially connected to their natal colony (Blumstein et al.

376

377
2009). Thus, yearling females may seek to minimize the cost and rate of agonistic interactions from more central dominant females by providing alloparental care in a 'pay to stay' strategy.

The four complementary sets of analyses illustrate a divergent pattern, whereby affiliative interactions are costly and agonistic interactions are beneficial. These different findings may reflect alternative strategies individuals use to increase their reproductive success (Mendl et al. 1992, Kinahan and Pillay 2008). More dominant mothers may aim to maximize their agonistic centrality, which may win them alloparental helpers, while more subordinate mothers may decrease their affiliative interactions and aim to be more socially isolated, potentially decreasing bullying and competition.

The divergent effects of agonistic and affiliative maternal relationships are consistent across the first summer and the first year of a pup's life. Affiliative instrength is significantly negatively associated with offspring summer and yearly survival, while agonistic path length has a significant positive effect. This is particularly remarkable given the different common causes of mortality in the summer (predation, Van Vuren 2001) and the winter (unsuccessful hibernation, Schwartz et al. 1998) and the different traits and abilities needed to survive these periods. Our models may reflect a general reality for marmots, that engaging in agonistic behavior is more beneficial than affiliative behavior. However, given that yearly survival is the sum of summer and winter survival, the results for yearly survival are partly driven by the summer effect. 
predation index. The ten significant interaction terms indicate that a maternal social measure that increases pup survival in one environment may have no effect on or even decrease survival in another environment, highlighting the importance of context on social benefits. For example, agonistic maternal path length has a positive effect on pup survival in the summer survival model, but the interaction between path length and valley position in the same model is negative. This means that agonistic maternal path length actually has a negative effect on pup survival in up valley environments. These results highlight the highly context dependent nature of the positive and negative effects of sociality. Thus, general statements about the benefits and costs of maternal social integration will not be applicable to all marmots in all environments. Rather, it is essential that studies on sociality are placed within an environmental context to accurately interpret their effects. significant interactions between predation index and maternal social network measure are

411 positive, meaning that in low predation environments, higher maternal social connectivity

412 and integration in both affiliative or agonistic networks has a more consistent, positive 413 effect on offspring outcomes, compared to high predation environments. Pinho et al.'s 414 (2019) work on fecal glucocorticoids and maternal behavior offers a potential mechanism 415 for this phenomenon. More social mothers in lower predation environments have lower 416 stress levels, and pups born to mothers with lower stress levels are more likely to survive. 417 However, mothers in these environments may have lower stress levels precisely because 
418 they benefit from conspecific help through alloparental care, as is the case in humans

419 (Balaji et al. 2007). The effect of interactions between valley position and maternal

420 affiliative and agonistic social network measures is also consistent: in up valley

421 environments, increased maternal sociality decreased pup survival. This may be caused

422 by a combination of the negative influence of sociality on over winter survival (Schwartz

423 et al. 1998) and longer winter conditions up valley (Van Vuren and Armitage 1991,

424 Blumstein et al. 2004).

This study adds to a small but growing body of literature documenting the highly

426

427 
440 variables may not always be adaptive (Badyaev 2005, Ghalambor et al. 2007) or even be

441 possible (DeWitt et al. 1998). Furthermore, unlike our approach, these studies used

442 relatively crude descriptors of social dynamics, such as group size, cohesion, and

443 agonistic behavior, that do not capture the complexity of an individual's social

444 relationships or the structure of the overall network (Wey et al. 2008, Kurvers et al.

445 2014).

446 We therefore suggest that sociality must be studied in a context-dependent

447 manner. The social network approach, used in this study (whereby individuals' specific

448 social network measures - calculated using observed social interactions - are analyzed as

449 possible predictors of life history traits) is a promising method to quantify and study an

450 individuals' social environment (Blumstein 2013). Although using social networks to

451 study context-dependent sociality has largely been applied to marmots (e.g., Wey and

452 Blumstein 2010, Yang et al. 2017, Mady and Blumstein 2017, Blumstein et al. 2018), its

453 use should not be restricted to facultatively social species. Obligately social species likely

454 experience many of the same context dependent sociality costs and benefits as facultative

455 social species (Lacey 2004, Maestripieri and Georgiev 2016), although the costs may be

456 more rare and ultimately outweighed by the benefits (Lutermann et al. 2013). This type of

457 analysis may be particularly fruitful in species where populations experience different

458 predation pressures or have significant life history differences. Moving forward, research

459 on how social animals are affected by their environments will be particularly important as

460 habitats change at unprecedented rates due to human use, fragmentation, and climate

461 change. 


\section{Funding}

463 This work was supported by the National Science Foundation (Research Experience for

464 Undergraduates fellowship to A.P.M; Graduate Research Fellowship grant number DGE-

4651650604 to D.M.W; grant numbers I.D.B.R.-0754247, D.E.B.-1119660, and 1557130 to

466 D.T.B., as well as D.B.I. 0242960, 0731346, and 1226713 to Rocky Mountain Biological

467 Laboratory); the National Geographic Society; the Animal Behavior Society (Student

468 Research Grant to D.M.W); the American Society of Mammologists (Grants-in-Aid of

469 Research to D.M.W); University of California, Los Angeles (Ecology and Evolutionary

470 Biology Fellowship to D.M.W); and the Rocky Mountain Biological Laboratory

471 (research fellowship to D.T.B.).

\section{Acknowledgements}

474 We are grateful to all marmoteers who collected data over many years, and the Rocky

475 Mountain Biological Laboratory (RMBL) which has helped facilitate this research.

476

477 Data availability: Code and data is available on OSF

https://doi.org/10.17605/OSF.IO/WC3NQ.

Ethics: All procedures were approved under research protocol ARC 2001-191-01 by the 
485 Conflict of interest: We declare no competing interests.

486

Author contributions: A.P.M., D.M.W., and D.T.B. conceived the project. All authors

488

489

490

collected data and designed the data analyses. A.P.M. analyzed the data and wrote the first draft of the manuscript. All authors contributed to subsequent revisions.

\section{References}

Armitage KB. 1982. Yellow-bellied marmot. In: Davis PDE, editor. CRC handbook of census methods for terrestrial vertebrates. Boca Raton, Florida: CRC Press. p. 148-149.

Armitage KB. 1987. Do female yellow-bellied marmots adjust the sex ratios of their offspring? The American Naturalist. 129:501-519.

Armitage KB. 1991. Social and population dynamics of yellow-bellied marmots: results from long-term research. Annual Review of Ecology and Systematics. 22:379407.

Armitage KB. 2014. Marmot biology: sociality, individual fitness, and population dynamics. England: Cambridge University Press.

Badyaev AV. 2005. Stress-induced variation in evolution: from behavioural plasticity to genetic assimilation. Proceedings of the Royal Society B: Biological Sciences. 272:877-886. 
Balaji AB, Claussen AH, Smith DC, Visser SN, Morales MJ, Perou R. 2007. Social support networks and maternal mental health and well-being. Journal of Women's Health. 16:1386-1396.

Barash DP. 1973. Social variety in the yellow-bellied marmot (Marmota flaviventris). Animal Behaviour. 21:579-584.

Blumstein DT, Armitage K. 1999. Cooperative breeding in marmots. OIKOS. 84:369382.

Blumstein DT, Fuong H, Palmer E. 2017. Social security: social relationship strength and connectedness influence how marmots respond to alarm calls. Behavioral Ecology and Sociobiology. 71:145.

Blumstein DT, Im S, Nicodemus A, Zugmeyer C. 2004. Yellow-bellied marmots (Marmota flaviventris) hibernate socially. Journal of Mammalogy. 85:25-29.

Blumstein DT, Keeley KN, Smith JE. 2016. Fitness and hormonal correlates of social and ecological stressors of female yellow-bellied marmots. Animal Behaviour. 112:111.

Blumstein DT, Wey TW, Tang K. 2009. A test of the social cohesion hypothesis: interactive female marmots remain at home. Proceedings of the Royal Society B: Biological Sciences. 276(1669): 3007-3012.

Blumstein DT, Williams DM, Lim AN, Kroeger S, Martin JGA. 2018. Strong social relationships are associated with decreased longevity in a facultatively social mammal. Proceedings of the Royal Society B: Biological Sciences. 285:20171934. 
527 Brashares JS, Arcese P. 2002. Role of forage, habitat and predation in the behavioural plasticity of a small African antelope. Journal of Animal Ecology. 71:626-638.

529

530

531

532 vertebrates. Science. 296:69-72.

Clutton-Brock TH, Parker GA. 1995. Punishment in animal societies. Nature. 373:209216.

DeWitt TJ, Sih A, Wilson DS. 1998. Costs and limits of phenotypic plasticity. Trends in Ecology \& Evolution. 13:77-81.

Dey CJ, Reddon AR, O’Connor CM, Balshine S. 2013. Network structure is related to social conflict in a cooperatively breeding fish. Animal Behaviour. 85:395-402.

Diesel R. 1989. Parental care in an unusual environment: Metopaulias depressus (Decapoda: Grapsidae), a crab that lives in epiphytic bromeliads. Animal Behaviour. 38:561-575.

Ellis L. 1995. Dominance and reproductive success among nonhuman animals: a crossspecies comparison. Ethology and Sociobiology. 16:257-333.

Fuong H, Blumstein DT. 2019. Social security: less socially connected marmots produce noisier alarm calls. Animal Behaviour. 154:131-136. 
547 Ghalambor CK, McKay JK, Carroll SP, Reznick DN. 2007. Adaptive versus nonadaptive phenotypic plasticity and the potential for contemporary adaptation in new environments. Functional Ecology. 21:394-407.

Grandinson K. 2005. Genetic background of maternal behaviour and its relation to offspring survival. Livestock Production Science. 93:43-50. social rodent. Ethology. 117:573-585.

Lacey EA. 2004. Sociality reduces individual direct fitness in a communally breeding rodent, the colonial tuco-tuco (Ctenomys sociabilis). Behavioral Ecology and Sociobiology. 56:449-457.

Lennartz MR, Hooper RG, Harlow RF. 1987. Sociality and cooperative breeding of redcockaded woodpeckers, Picoides borealis. Behavioral Ecology and Sociobiology. 20:77-88. 
Lonstein JS, Lévy F, Fleming AS. 2015. Common and divergent psychobiological mechanisms underlying maternal behaviors in non-human and human mammals. Hormones and Behavior. 73:156-185.

Lutermann H, Bennett NC, Speakman JR, Scantlebury M. 2013. Energetic benefits of sociality offset the costs of parasitism in a cooperative mammal. PLOS ONE. 8:e57969.

Mady RP, Blumstein DT. 2017. Social security: are socially connected individuals less vigilant? Animal Behaviour. 134:79-85.

Maestripieri D, Georgiev AV. 2016. What cortisol can tell us about the costs of sociality and reproduction among free-ranging rhesus macaque females on Cayo Santiago. American Journal of Primatology. 78:92-105.

Marino A. 2010. Costs and benefits of sociality differ between female guanacos living in contrasting ecological conditions. Ethology. 116:999-1010.

Mendl M, Zanella AJ, Broom DM. 1992. Physiological and reproductive correlates of behavioural strategies in female domestic pigs. Animal Behaviour. 44:1107-1121.

Montero APM, Williams DM, Martin JGA, Blumstein DT. 2020. More social female yellow-bellied marmots (Marmota flaviventer) have enhanced summer survival. Animal Behaviour. 160:113-119.

Moore CL, Power KL. 1992. Variation in maternal care and individual differences in play, exploration, and grooming of juvenile Norway rat offspring. Developmental Psychobiology. 25:165-182.

Newman M. 2018. Networks. England: Oxford University Press. 
O’Connor DE, Shine R. 2004. Parental care protects against infanticide in the lizard Egernia saxatilis (Scincidae). Animal Behaviour. 68:1361-1369.

Pinho GM, Ortiz-Ross X, Reese AN, Blumstein DT. 2019. Correlates of maternal glucocorticoid levels in a socially flexible rodent. Hormones and Behavior. 116:104577.

Pusey A. 1997. The influence of dominance rank on the reproductive success of female chimpanzees. Science. 277:828-831.

Riedman ML. 1982. The evolution of alloparental care and adoption in mammals and birds. The Quarterly Review of Biology. 57:405-435.

le Roux A, Cherry MI, Manser MB. 2008. The audience effect in a facultatively social mammal, the yellow mongoose, Cynictis penicillata. Animal Behaviour. 75:943949.

Russell AF, Clutton-Brock TH, Brotherton PNM, Sharpe LL, Mcilrath GM, Dalerum FD, Cameron EZ, Barnard JA. 2002. Factors affecting pup growth and survival in cooperatively breeding meerkats Suricata suricatta. Journal of Animal Ecology. $71: 700-709$.

Ryer CH, Olla BL. 1996. Social behavior of juvenile chum salmon, Oncorhynchus keta, under risk of predation: the influence of food distribution. Environmental Biology of Fishes. 45:75-83.

Schwartz OA, Armitage KB, Van Vuren D. 1998. A 32-year demography of yellowbellied marmots (Marmota flaviventris). Journal of Zoology. 246:337-346. 
611 Silk JB, Beehner JC, Bergman TJ, Crockford C, Engh AL, Moscovice LR, Wittig RM,

612

613 Seyfarth RM, Cheney DL. 2009. The benefits of social capital: close social bonds among female baboons enhance offspring survival. Proceedings of the Royal Society B: Biological Sciences. 276:3099-3104.

da Silva Mota M, Franci CR, de Sousa MBC. 2006. Hormonal changes related to paternal and alloparental care in common marmosets (Callithrix jacchus). Hormones and Behavior. 49:293-302.

Sinn DL, While GM, Wapstra E. 2008. Maternal care in a social lizard: links between female aggression and offspring fitness. Animal Behaviour. 76:1249-1257.

Solomon NG, French JA. 1997. Cooperative Breeding in Mammals. England: Cambridge University Press.

Stern JM, Lonstein JS. 2001. Neural mediation of nursing and related maternal behaviors. Progress in Brain Research. 133:263-278.

Svendsen GE. 1974. Behavioral and environmental factors in the spatial distribution and population dynamics of a yellow-bellied marmot population. Ecology. 55:760771.

Van Vuren DH. 2001. Predation on yellow-bellied marmots (Marmota Flaviventris). American Midland Naturalist. 145:94-100.

Vuren DV, Armitage KB. 1991. Duration of snow cover and its influence on life-history variation in yellow-bellied marmots. Canadian Journal of Zoology. 69:17551758. 
632 Wasserman S, Faust K. 1994. Social Network Analysis: Methods and Applications.

633 England: Cambridge University Press.

634 Wey TW, Blumstein DT. 2010. Social cohesion in yellow-bellied marmots is established 635 through age and kin structuring. Animal Behaviour. 79:1343-1352.

636 Wey TW, Blumstein DT, Shen W, Jordan F. 2008. Social network analysis of animal

637 behaviour: a promising tool for the study of sociality. Animal Behaviour. 75:333$638 \quad 344$.

639 Yang WJ, Maldonado-Chaparro AA, and Blumstein DT. 2017. A cost of being amicable 640 in a hibernating mammal. Behavioral Ecology. 28:11-19. 
641 Figure 1. Figures illustrate significant relationships between maternal social network

642 measures and pup summer survival based on affiliative interactions. a. Instrength, b.

643 Instrength*predation index interaction, c. Indegree*predation index interaction, $\mathbf{d}$.

644 Outcloseness*predation index interaction, e. Local clustering*predation index interaction,

645 f. Outcloseness*valley position interaction, $\mathbf{g}$. Negative average shortest path length*

646 valley position interaction. Each point represents a pup's binary survival and the pup's

647 mother's social network measure strength. Solid lines show model predictions and

648 shading depicts the $95 \%$ confidence interval. Lines in graphs b. - e. depict model

649 predictions for low predation (low) and high predation (high) environments. Lines in

650 graphs f. and g. model predictions for up valley (uv) and down valley (dv) environments.

651 See text for a full description of social measures.

652

Figure 2. Figure illustrates significant relationships between maternal social network

654

655

656

657

658

659

660

661

662 measure instrength and pup yearly survival based on affiliative interactions. Each point in

represents a pup's binary survival and the pup's mother's social network measure

strength. The solid line shows the model predictions and shading depicts the $95 \%$

confidence interval. See text for a full description of social measures.

Figure 3. Figures illustrate significant relationships between maternal social network

measures and pup summer survival based on agonistic interactions. a. Negative average

shortest path length, b. Negative average shortest path length*valley position interaction,

c. Outdegree*valley position interaction, d. Outcloseness*valley position interaction. 
663 Each point represents a pup's binary survival and the pup's mother's social network

664 measure strength. Solid lines show model predictions and shading depicts the $95 \%$

665 confidence interval. Lines in graphs b. - d. depict model predations for up valley (uv) and

666 down valley (dv) environments. See text for a full description of social measures.

667

Figure 4. Figures illustrate significant relationships between maternal social network

669 measures and pup yearly survival based on agonistic interactions. a. Negative average

670 shortest path length, b. Negative average shortest path length*valley position interaction.

671 Each point represents a pup's binary survival and the pup's mother's social network

672 measure strength. Solid lines show model predictions and shading depicts the $95 \%$

673 confidence interval. Lines in graph b. depicts model predations for up valley (uv) and

674 down valley (dv) environments. See text for a full description of social measures. 
Table 1. Association between maternal social network measures and pup survival, broken down by summer and yearly survival and affiliative and agonistic networks.

677

\begin{tabular}{|c|c|c|c|c|}
\hline \multirow{2}{*}{$\begin{array}{l}\text { Social Network } \\
\text { Measure }\end{array}$} & \multicolumn{2}{|c|}{ Affiliative Interactions } & \multicolumn{2}{|c|}{ Agonistic Interactions } \\
\hline & Summer & Yearly & Summer & Yearly \\
\hline Indegree & 0 & 0 & 0 & 0 \\
\hline Outdegree & 0 & 0 & 0 & 0 \\
\hline Betweenness & 0 & 0 & 0 & 0 \\
\hline Outcloseness & 0 & 0 & 0 & 0 \\
\hline Incloseness & 0 & 0 & 0 & 0 \\
\hline Local Clustering & 0 & 0 & 0 & 0 \\
\hline $\begin{array}{l}\text { Negative Average } \\
\text { Shortest Path Length }\end{array}$ & 0 & 0 & $*+*$ & $*+*$ \\
\hline Eigenvector Centrality & 0 & 0 & 0 & 0 \\
\hline Outstrength & 0 & 0 & 0 & 0 \\
\hline Instrength & $*_{-} *$ & $*$ & 0 & 0 \\
\hline
\end{tabular}


bi6Rxiv preprint doi: https://doi.org/10.1101/2021.01.28.428660; this version posted January 29, 2021. The copyright holder for this preprint (which was not certified by peer review) is the author/funder, who has granted bioRxiv a license to display the preprint in perpetuity. It is made available under aCC-BY-NC 4.0 International license.

a

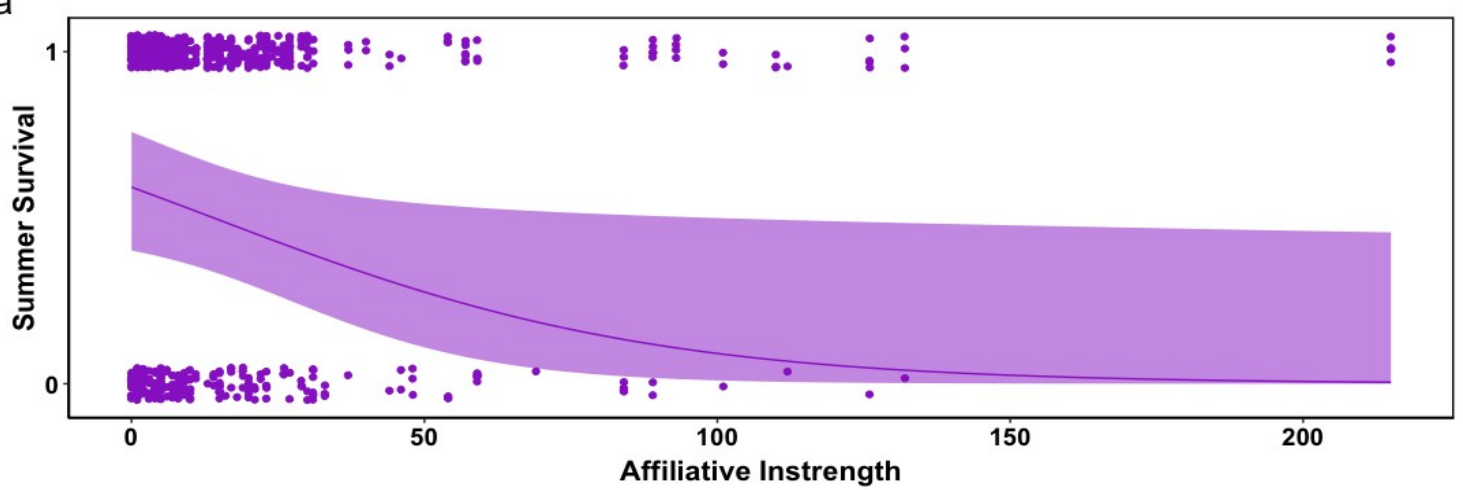

b

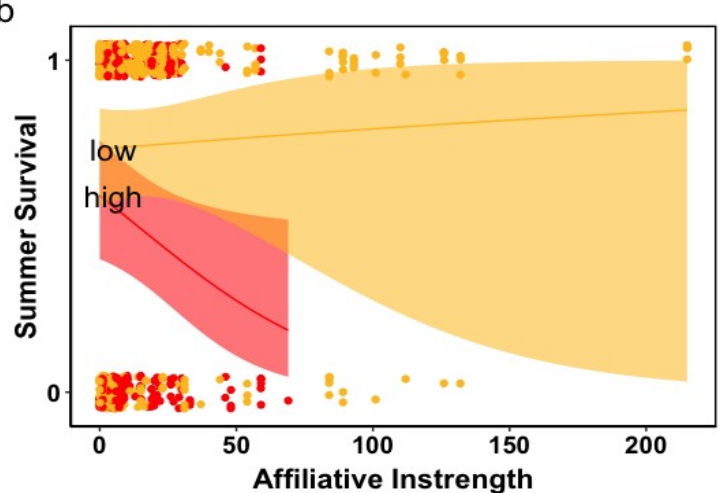

d

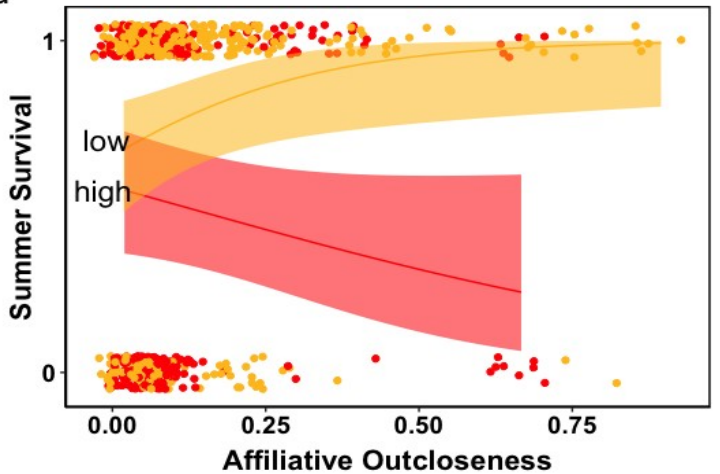

f

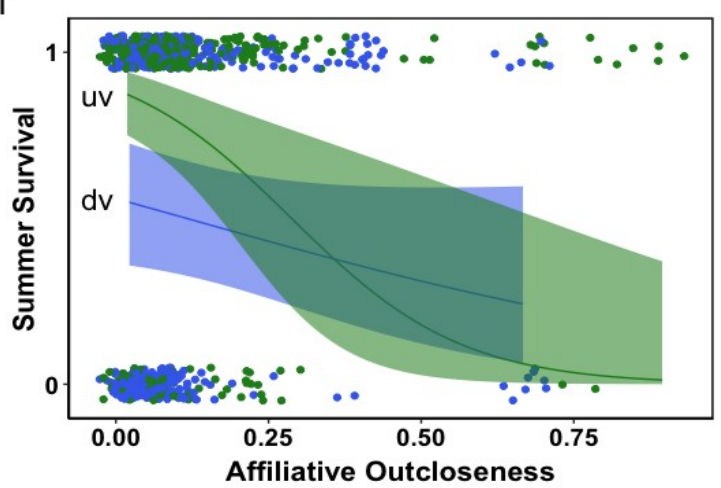

678

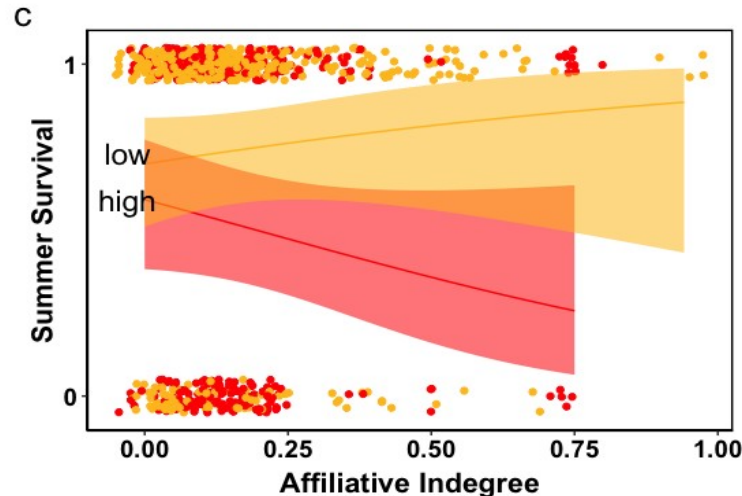

e

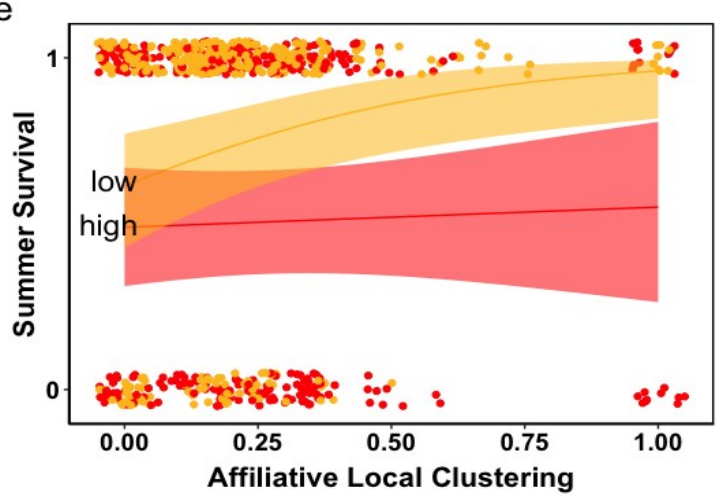

g

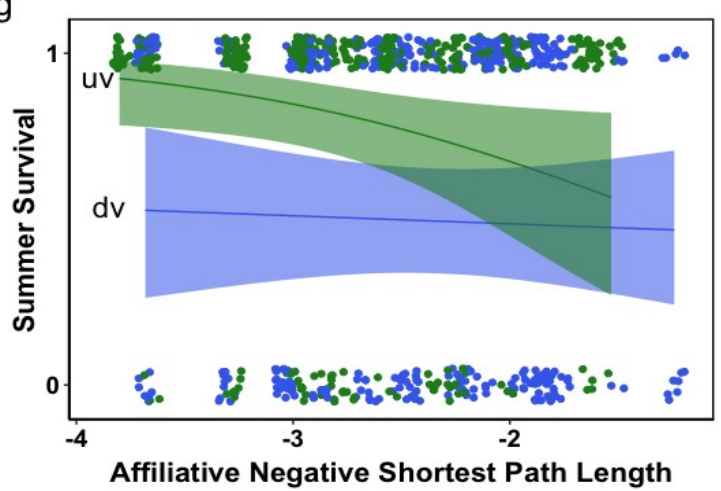


bi $\{$ Pxiv preprint doi: https://doi.org/10.1101/2021.01.28.428660; this version posted January 29, 2021. The copyright holder for this preprint (which was not certified by peer review) is the author/funder, who has granted bioRxiv a license to display the preprint in perpetuity. It is made available under aCC-BY-NC 4.0 International license.

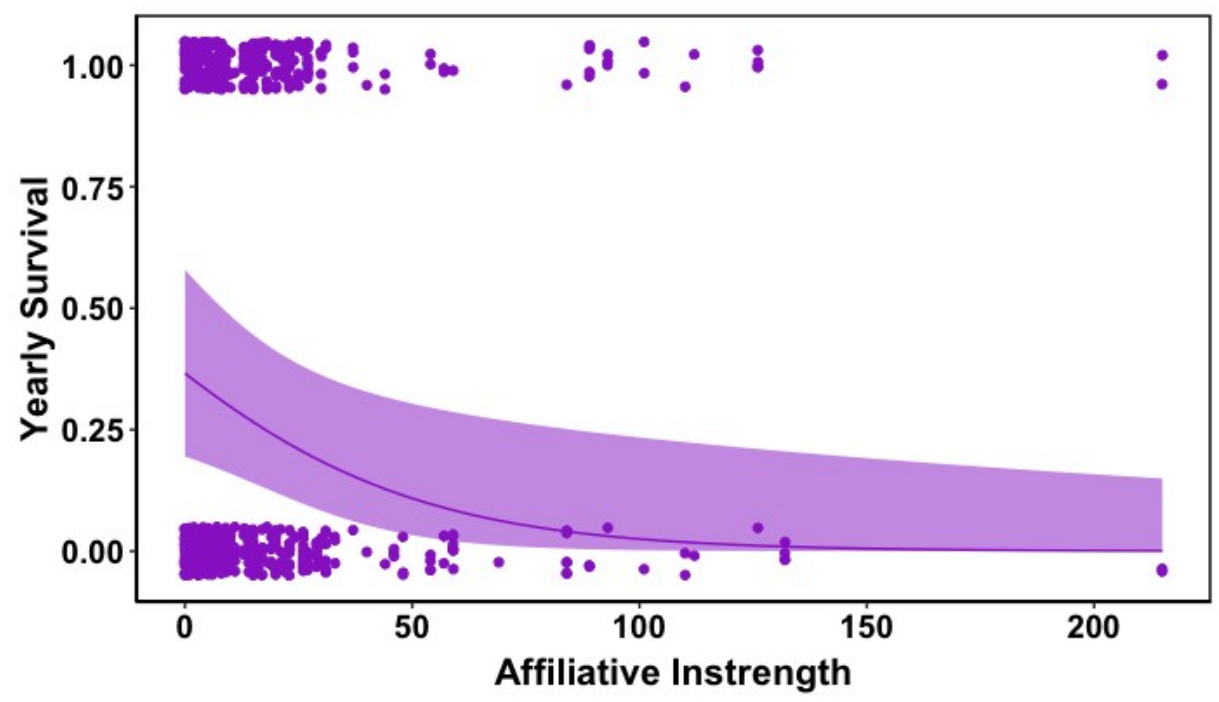

680

681

682

683

a

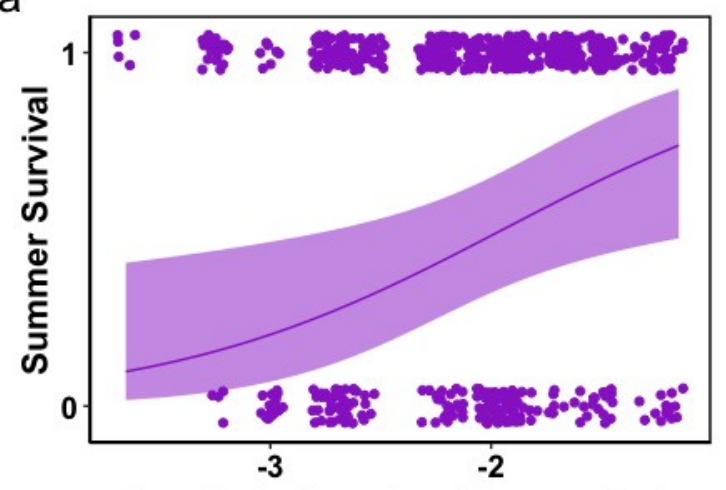

Agonistic Negative Shortest Path

C

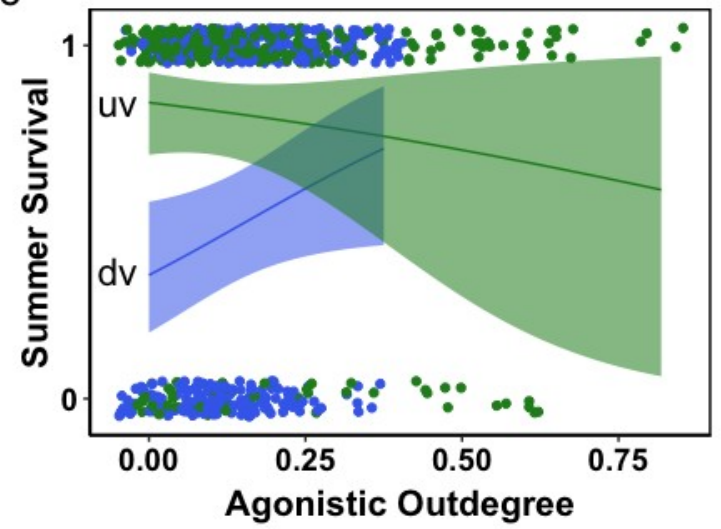

b

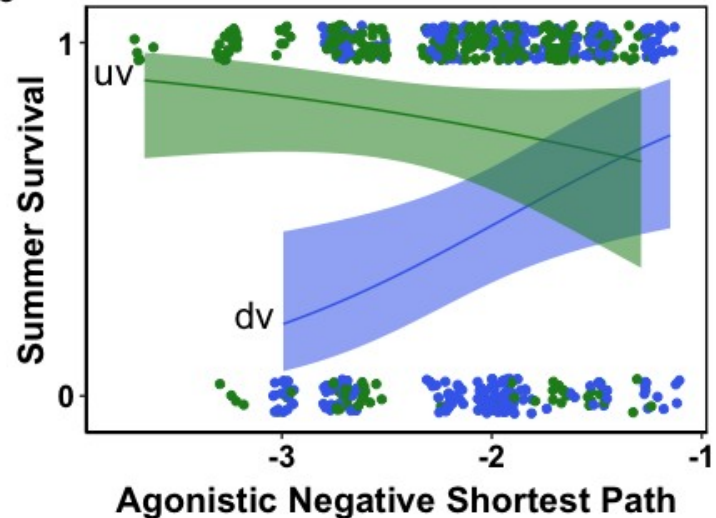

d

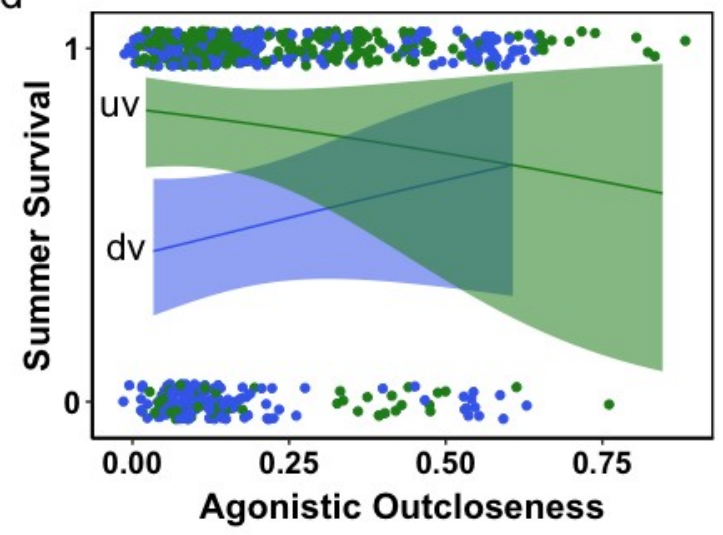

685

Figure 3. 
biofAxiv preprint doi: https://doi.org/10.1101/2021.01.28.428660; this version posted January 29, 2021. The copyright holder for this preprint (which was not certified by peer review) is the author/funder, who has granted bioRxiv a license to display the preprint in perpetuity. It is made available under aCC-BY-NC 4.0 International license.

a

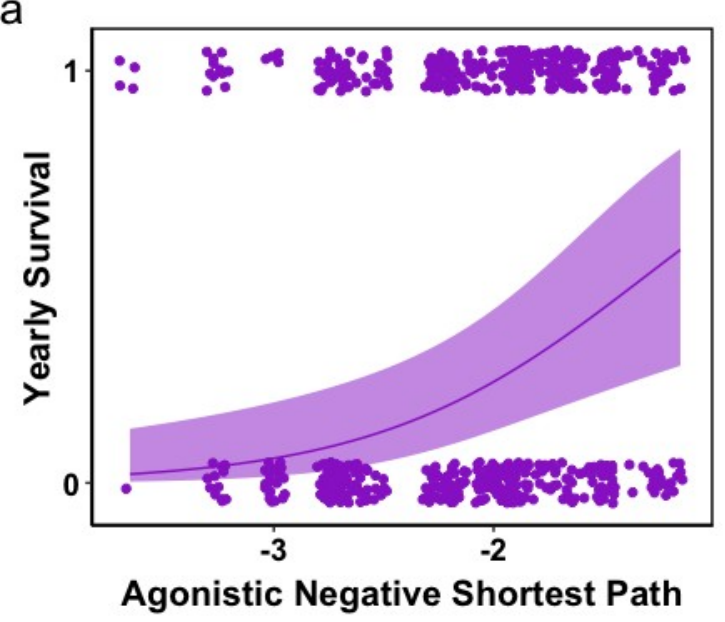

b

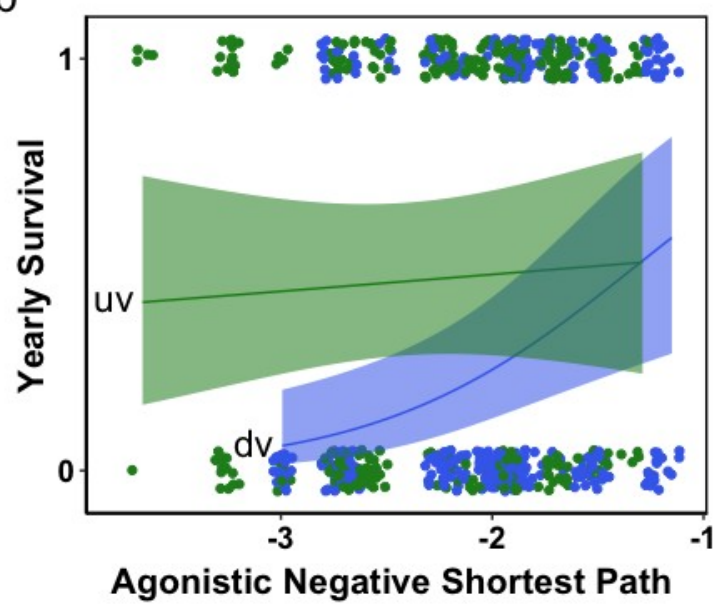

687 Figure 4. 